MUSICA THEORICA 2020, V. 5.2

SCIENTIFIC ARTICLE

Submission date: Aug/20/2020

Acceptance date: Sep/20/2020

\title{
A Conversation with Robert Hatten about A Theory of Virtual Agency for Western Art Music
}

\author{
Robert Hatten \\ Maria Lúcia Machado Pascoal \\ Cristina Capparelli Gerling \\ Flavio Santos Pereira \\ Diósnio Machado Neto \\ Guilherme Sauerbronn de Barros \\ Paulo de Tarso Salles
}

\begin{abstract}
From August to October 2020, the Brazilian Society for Music Theory and Analysis (TeMA) held a series of five online meetings, each featuring a well-stablished theorist who presented one of his/her recent publications. Following the guest speaker's presentation, a discussion session ensued, featuring guests from TeMA. On August 20th, TeMA received Robert Hatten to open the series, who was invited to talk about his most recent book: $A$ Theory of Virtual Agency for Western Art Music (2018). Six guests from TeMA joined Hatten for the discussion session: Maria Lúcia Machado Pascoal, Cristina Capparelli Gerling, Flavio Santos Pereira, Diósnio Machado Neto, Guilherme Sauerbronn de Barros, and Paulo de Tarso Salles. Aiming at bringing Hatten's presentation and the lively ensuing discussion to a wider audience, this essay presents an edited transcription of this meeting. ${ }^{1}$
\end{abstract}

Keywords: Agency. Virtualizing. Embodying. Fictionalizing. Interiorizing.

\section{Robert Hatten's opening remarks}

Thank you for the kind invitation to share my ideas with you this afternoon. It is fitting that my presentation on virtual agency should be delivered through this virtual medium, but the way in which I have theorized virtual agency has more to do with what happens in the mind of a listener, as staged by a composer, than with the virtuality of a medium of communication such as

1 The video recording of this meeting is available at
https://www.youtube.com/watch? $\mathrm{v}=$ maKOPQsyRYQ\&t=1s.


Zoom, in which I am nevertheless actually present to your eyes and ears in real time. In music, what makes our experience of agency "virtual" is that it involves the attribution of energy and intention to an otherwise non-existent entity.

There are several ways in which we as listeners infer agency. First, we hear the movement of tones-itself an inference from mere succession to the energy that links sounds as performed-and as occurring in a virtual environment with properties analogous to our physical environment. We sense the weight of gravity toward a tonal platform, such as the tonic, and the energy it takes to ascend against that gravity. And the experience of meter is like a constantly refreshed environment in which downbeats and upbeats correlate with our physical sense of down and up. Listening to tonal movement within the constraints of a virtual gravitational field already suggests an analogy with human movement. And human gestures can be transduced by performers when they energetically connect otherwise isolated pitches, creating the dynamic shapes that we associate not only with movement, but the affective character of that movement, as gesture. Successive movements in tonal music may imply goals that can be either immediately realized or indefinitely postponed, or even frustrated altogether. Contrasting movements can suggest competing sources, and hence analogues with dialogue or conflict, leading to dramatic trajectories. Finally, embodied movements can also be sensed as the movements of thoughts and feelings; they can in this sense become "enminded."

What I have just described can be theorized in terms of four transformative inferences:

1. Virtualizing: when we hear movement as action, we infer a virtual actant, that unspecified source of energy capable of producing the energy we hear.

2. Embodying: when we hear characteristic gestures and intentional movement, it is possible to infer a virtual (human) agent possessing those characteristics and intentions.

3. Fictionalizing: when we hear one or more agents interacting or pursuing goals, especially if overcoming obstacles, we are likely to hear virtual agents as virtual actors with roles in a fictional drama.

4. Interiorizing: when we move from embodiment to "enmindment," as characterized by the internalizing of movements, energies, actions, gestures, intentions, and even dramatic roles, we can infer virtual subjectivity, as a kind of ongoing consciousness involving the development of "feelingful 
thought," or engaging "passions of the mind" (two locutions that can help us avoid the unfortunate dichotomy of emotion and reason in Western thought). Characteristic cues for interiorization, as implying virtual subjectivity, include rhetorical gestures, which can suggest shifts in level of discourse; or fermatas and rests, which afford time for reflection.

Some qualifications may be helpful at this point:

1. These stages may be theorized as progressive, but I am not claiming that listeners necessarily go through each stage systematically in their aural cognition, or consciously in their attempt to interpret musical meaning. I would suspect that many of these inferences are so automatic as to be unnoticed or unremarkable. And since competency in a musical style is historical, learned, and aesthetic, it would be difficult to empirically test these claims without introducing bias in the experiment.

2. Historically, some musical styles may not support certain levels of agency. Aesthetically, some music, especially in a lyrical as opposed to dramatic mode, may not give rise to virtual actors in a fictionalized story or narrative. Culturally, these stages are not necessarily universal, and they may be fused into fewer stages. For example, some cultures may not distinguish embodiment from enmindment since they do not experience a body/mind separation. Viewing Western music history through an agential lens, however, helps one construct a history of the progressive compositional staging of virtual agential effects. In effect, rather than constructing a history of abstract forms and structures, one might focus on reconstructing the expressive and agential motivations for innovations in form and structure.

3. Philosophically, breaking agency into these different inferences can counter the arguments against a more simplistic notion of a persona. The theory helps clarify just how much is being claimed, with reference to musical evidence.

4. Complicating this view of virtual agency is the obvious issue of actual agency: real composers, performers, and listeners, all of whom engage in some way with the virtualized agencies and subjectivities that are possible to infer from the music. In later chapters of the book I address some of these issues, introducing performative agency as the stance taken by an actual performer to the virtual agencies that may be inferred and projected-and when significant projection of the performer's agency may or may not be most appropriate. 
5. Finally, shifts in level of discourse, along with compositional frames, offer cues for narrative agency, which it is possible to stage as part of the musical discourse. However, performers also assume a degree of narrative agency in their personalized projection of virtual/fictive musical stories, and composers may assume a degree of narrative agency in their manipulation of listeners' interpretations of, e.g., characters in an opera.

6. For the most part, I have constructed this theory to accommodate non-texted instrumental works in the Western tonal tradition, but in the book I also include examples from song and opera literature, and from pre- and posttonal repertories, to give an indication of its practical extensions. The theory could be adapted to serve other repertories, as well.

Having provided a brief overview of the theory, I would like to explore some musical examples with you. The first example, as you may recall, is the first one in the book, Beethoven's piano sonata in F major, Op. 10 no. 2/i (see Ex. 1a). As you can see, mm. 1-4 are composed by Beethoven. I decided to try out a typical eight-bar sentence construction by taking those opening motives of what I would call the presentation phase and accelerating them-starting in $\mathrm{m} .5$ and increasing the surface rhythm to create a true continuation structure, then moving in mm. 7-8 to a clear cadence. In this case, a half cadence so that the whole sentence structure is like an antecedent of an implied sixteen-bar compound period.

As far as agency, I wanted to use this example to develop from my theories of types of gesture: spontaneous gesture (opening two chords), rhetorical gesture (when you have a rest that interrupts the otherwise unmarked flow of the discourse), dialogical gestures (where the triplet turn figure provides a kind of dialogical answering to the first gesture), and even the hierarchization of gestures (because you have the first double gesture on the tonic answered by the same double gesture on the dominant $-\mathrm{V}^{6}$ ).

So, if we go to the next example, this is what Beethoven actually wrote (see Ex. 1b). You could see his continuation is not at all what I suggested with my own. My composed continuation suggested that the first four measures were in some ways a buffa kind of topical gesturing - very light-hearted, playful - and I continued with taking that gestural play over the top, as it were, in the continuation towards the climax of sheer hilarity, if you will. Beethoven swirls in another direction. 

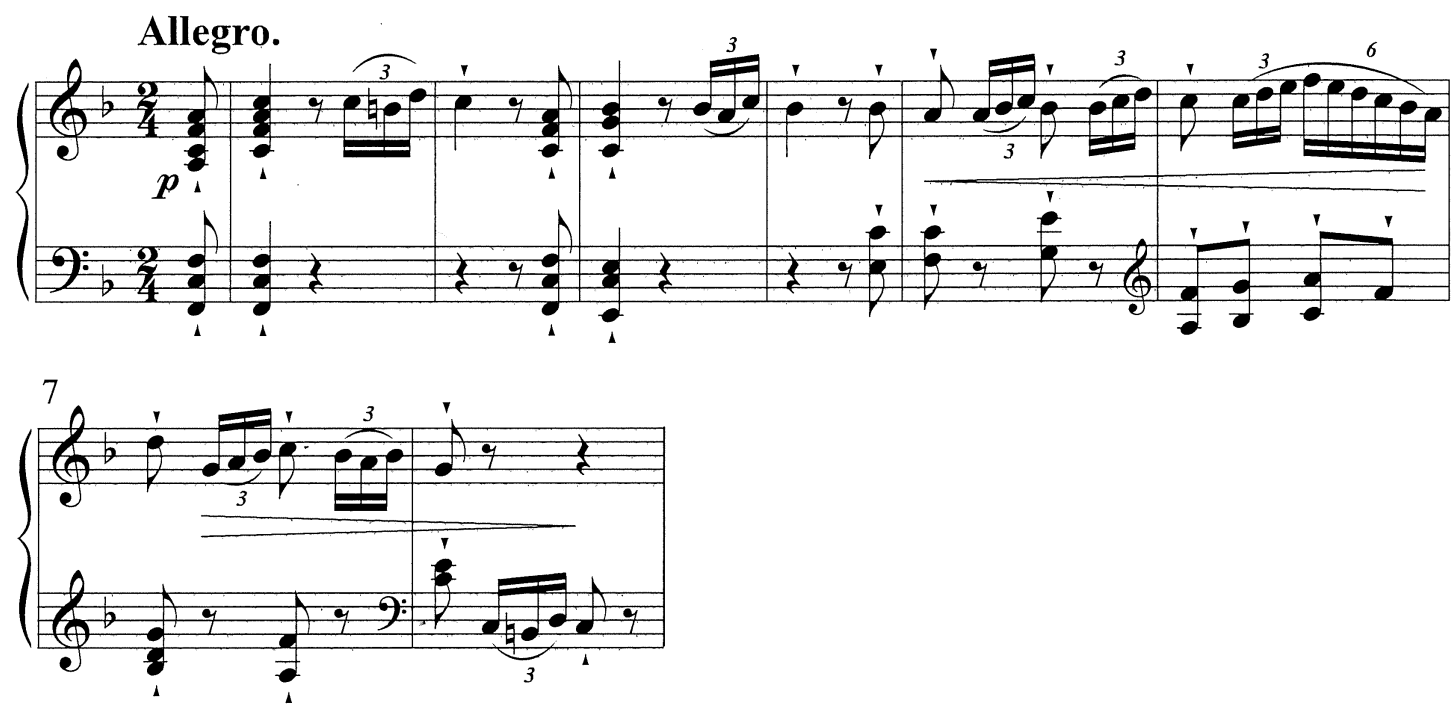

Example 1a: Beethoven, Piano Sonata in F Major, Op. 10, no. 2, i (mm. 1-4 as composed by Beethoven; mm. 5-8 recomposed as continuation and cadence of a typical eight-bar sentence phrase structure). ${ }^{2}$

$$
\text { presentation (mm. } 1 \text { - 4) }
$$
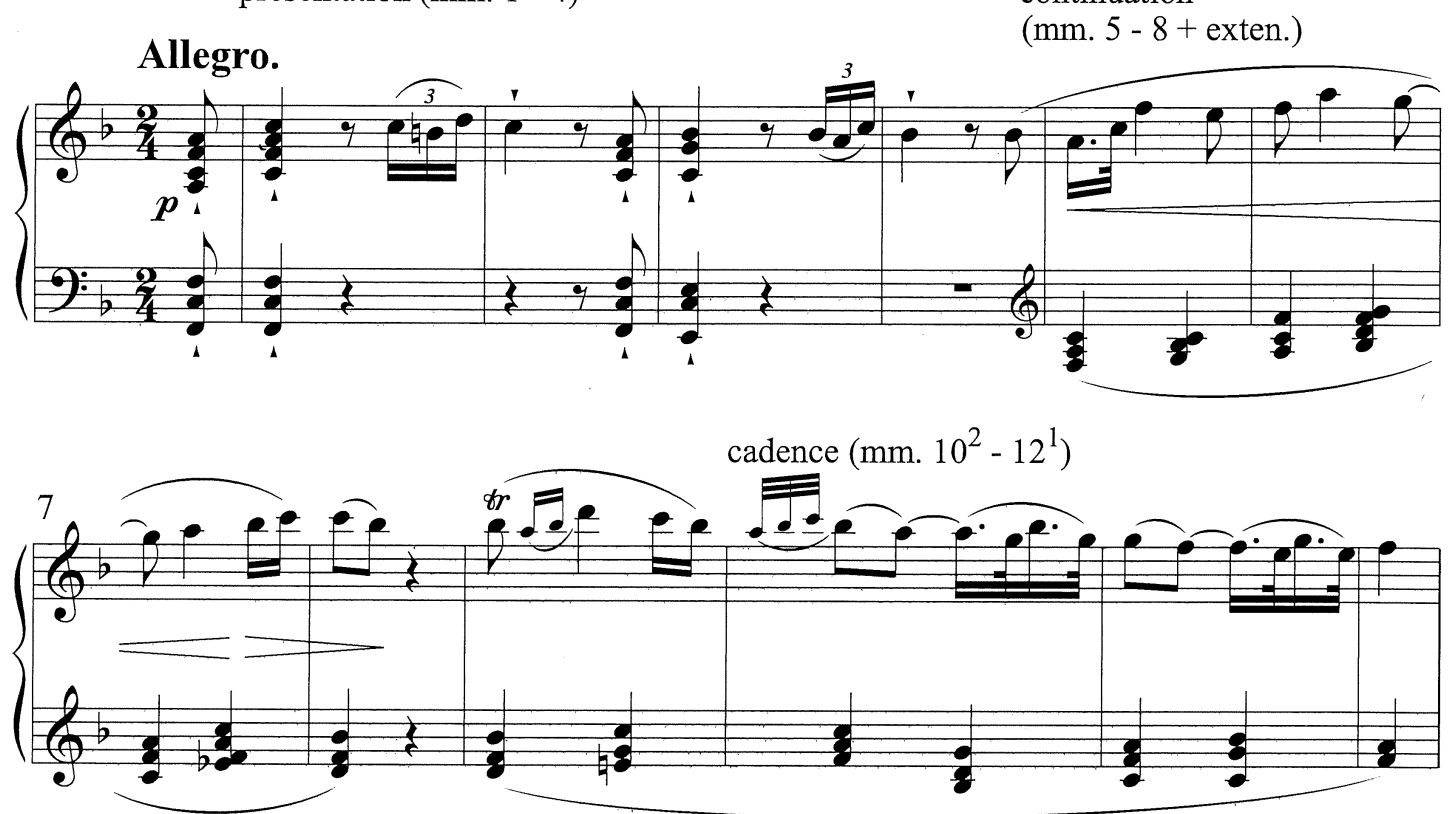

Example 1b: Beethoven, Piano Sonata in F Major, Op. 10, no. 2/i: main theme (mm. 112) as composed by Beethoven.

2 All the musical examples included in this transcription were exhibited during TeMA's online meeting on August $20^{\text {th }}, 2020$. 
If we look at this in terms of agency, we can certainly say that each gesture implies an actant. It is an action that implies an unspecified actant, simply that which acts. But, very quickly, we begin to move to the next level which is that of a notion of a human agent because as you would perform that very first gesture it already has so much affective character and suggests a human gesture, not just any unwitting action - a human gesture with some sort of intentionality. And perhaps, as we will see, that gesture might suggest something interrogative, as though you were asking a question: isn't this really this? or that really that? and then moving on from that point. Then, we have taken what could have been two opposing actors. The first two chords and the triplet turn as being in dialogue might have suggested two opposing virtual actors. But see how quickly we want to absorb those actors into a singular agency and perhaps even a singular subjectivity. In other words, a flow of consciousness in which everything comes together in that flow of conscious expressiveness.

What happens at m. 5 (where I have marked continuation) is a radical change of texture and of continuity, in spite of the connecting link of structural pitches ( $\mathrm{C}$ in $\mathrm{m} .1, \mathrm{~B} b$ in $\mathrm{m} .3$, and $\mathrm{A}$ in $\mathrm{m} .5$ ). There is clearly a Schenkerian, if you will, sense of voice-leading continuity that connects these two. And, of course, the tonic in $\mathrm{m} .5$ completes the tonic prolongation of the first four bars, but everything else is radically different. We have a clear lyrical melody on top, a hymn-like accompaniment in the blocked chords (and all of this lyrically legato). Notice that the melody introduces syncopations, the kind of Mozart rubato, if you will, that helps project expressively this melody against the accompanying chords. And, it begins to move progressively until $\mathrm{m}$. 7, where $\mathrm{Eb}$ in the bass suggests a reversal, a sudden turn towards the subdominant chord. At that point, we have reached a temporary climax on $\mathrm{C}$ to $\mathrm{B} b$ in $\mathrm{m} .8$ above that ${ }^{6}$ chord. Then, there's a rest.

Now, that is a great example of a rhetorical gesture. Rhetorical because unexpected the swirl towards the subdominant and with the rest we have a moment to absorb, to reflect upon that rhetorical gesture, and that is what leads us to a deeper level of subjectivity. That, in fact, is the staging of interiority through which we realize that perhaps this theme is not going to simply be so comical as I first suggested. Perhaps, we move towards a greater level or dimension of spiritual expressivity. 
Well, if that is the case, then we might begin to rethink the opening four bars as perhaps a tentatively posed question for which $\mathrm{m}$. 5 begins an answer. And, if we were to look at the recapitulation, we would discover that after a false recapitulation in D Major-in which we get all twelve bars of this themeBeethoven then begins a retransition with the first gesture moving to ii of $\mathrm{F}$ major, the second gesture to $\mathrm{V}^{7}$ of $\mathrm{F}$ major, and then repetition echoing of that triplet gesture three more times clearly makes it sound like a question to which finally we get to $\mathrm{F}$ major for the recapitulation. We hear $\mathrm{m} .5$ as the beginning of the recapitulation and the answer to that question. So, already in $\mathrm{m}$. 5, we can see that such a radical change of texture is in itself a rhetorical gesture. In the larger sense, that we are swirling from one kind of discourse to another and, in terms of sonata phrase structure or the phrase structure of the sentence (which is clearly expanded), we also have justification for this expansion because the continuation is going to begin an eight-bar hypermetric unit that will be supported by its use for the recapitulation. The eight-bar continuity across the rest to m. 8 -going on to $9,10,11$, and 12 to complete that eight bars-is made continuous by starting on the exact same chord, in the exact same position in $\mathrm{m}$. 9, and leading further to a beautiful expressive climax in $\mathrm{mm}$. 9 and 10. Alexandra Pierce (2007) would say this is a kind of cloud of climax. Not just one point, but the kind of climax field. That is all very expressive, almost a kind of fulfillment. So, that leads us onto cadential activity, beginning in the second half of $\mathrm{m} .10$, where we get the $\mathrm{ii}^{6} \mathrm{~V}^{6}{ }^{-7} \mathrm{I}$, and we have completed a sentence structure, a complete sentence as phrase.

Now, this expansion is so radical, an unexpected shift towards the lyrical aspect, that it begins to suggest a sense of freedom. Freedom from the objectivity of decorum, the Gallant periodicity, if you will, of the opening presentation phase (notice I say phase instead of phrase because it is simply a tonic prolongation). That sense of freedom suggests a kind of emotion. Even though we don't know what exactly this piece is about-we don't have a program for it (Beethoven declined to provide when Czerny asked for poetic programs for his sonatas. He thought about it and basically declined because whatever his initial inspirations may have been, music exists for us to engage with, with our own subjectivities and to provide the situation that will make this sense of freedom towards something more ecstatic, perhaps something more spiritually profound, leading up into the higher register). Whatever that is, we can engage with it and 
interpret it in numerable ways. The only thing that our hermeneutic-virtual, agential-analyses insist upon is that you will apply these understandings to something that follows the trajectory that mimes the curves and contours, the trajectory of the gestures and the virtual agential experiences of this passage. So, what can a performer add? Certainly, when I play this, I would like to play the first four bars rather perfunctorily although with a sly suggestion that maybe there is a hint of a question here for which already $\mathrm{m}$. 5 could be a potential answer and then that premise will be realized by Beethoven, as he stages it in the recapitulation.

Let's move on to our next example. Here we have Mozart's slow movement from a late piano sonata, one in which, by the way, Mozart is already beginning to explore developing variation. When Mozart was on his death bed, he said "I'm just learning how to compose and now I have to die". I wonder if he could have meant that he was learning about ways to create even greater continuity and to promote an ongoing musical discourse by evolving from initial thematic material. Anyway, what I have given you here is not what Mozart wrote as the first four bars of the slow movement, but instead what a lesser composer might have. This notion of a prototype which we can often use to suggest the normative form of a phrase before it gets expanded (see Ex. 2a). We could also use it for the normative form of a phrase before it gets expressively enhanced and we will see how Mozart enhances it. But first we see that it starts out with a very simple merger of voices, simple neighboring, and then parallel thirds that is already a good example of melos, although I did not use this example for that purpose in the book. In m. 2, we drop diatonically to a typical subdominant (ii ${ }^{6}$ chord in this case), moving to $\mathrm{V}^{6}$ of $\mathrm{V}$, and then on to the dominant structure of the third measure $\left(\mathrm{V}^{6}-7\right)$ and on to tonic. Very simple.

Let's look at the next example and see what Mozart has done to make this music come alive (see Ex. 2b). As you can see, the drop in $\mathrm{m} .2$ is no longer the innocent diatonic drop, but a much more tragically inflected drop that might suggest an external agency that has caused a reaction on the part of the internal agent that we were following. But, if we begin to realize, in a theme you could already have a dramatic trajectory, just four bars to create a dramatic trajectory, then we see our protagonist, our auctorial virtual agent, recovering very quickly from that dissonant drop with that beautiful, expressive turn figure which we saw climatic in the Beethoven. (Turn figures in Mozart and Beethoven are 
typically the most intimate and expressive of ornaments, and internalizing of ornaments as well.) Notice the turn figure is preceded by an anticipation and also a suspension. All three of these additions to our simple version above heighten its expressivity and make it more and more human and even subjectively internalized. Notice that this recovery is a very positive moment, so it gets the 43 suspension that we associate with the kind of religioso context as being spiritualizing. And then, having reached that wonderful recovery, almost in a gesture of "Oh, thank goodness", we have to accelerate to get to our cadence. So, very quickly, in a sort of shiver of delight, accelerating to the closure of the cadence. Notice how the cadence now gets expanded beyond its arrival on the downbeat in the left hand. Now both hands delay the ultimate cadential chord to the second beat. So, I use this example to talk about ways in which we can understand degrees and depths of emotional expressiveness even as part of the explanation involves virtual auctoriality and even subjectivity.

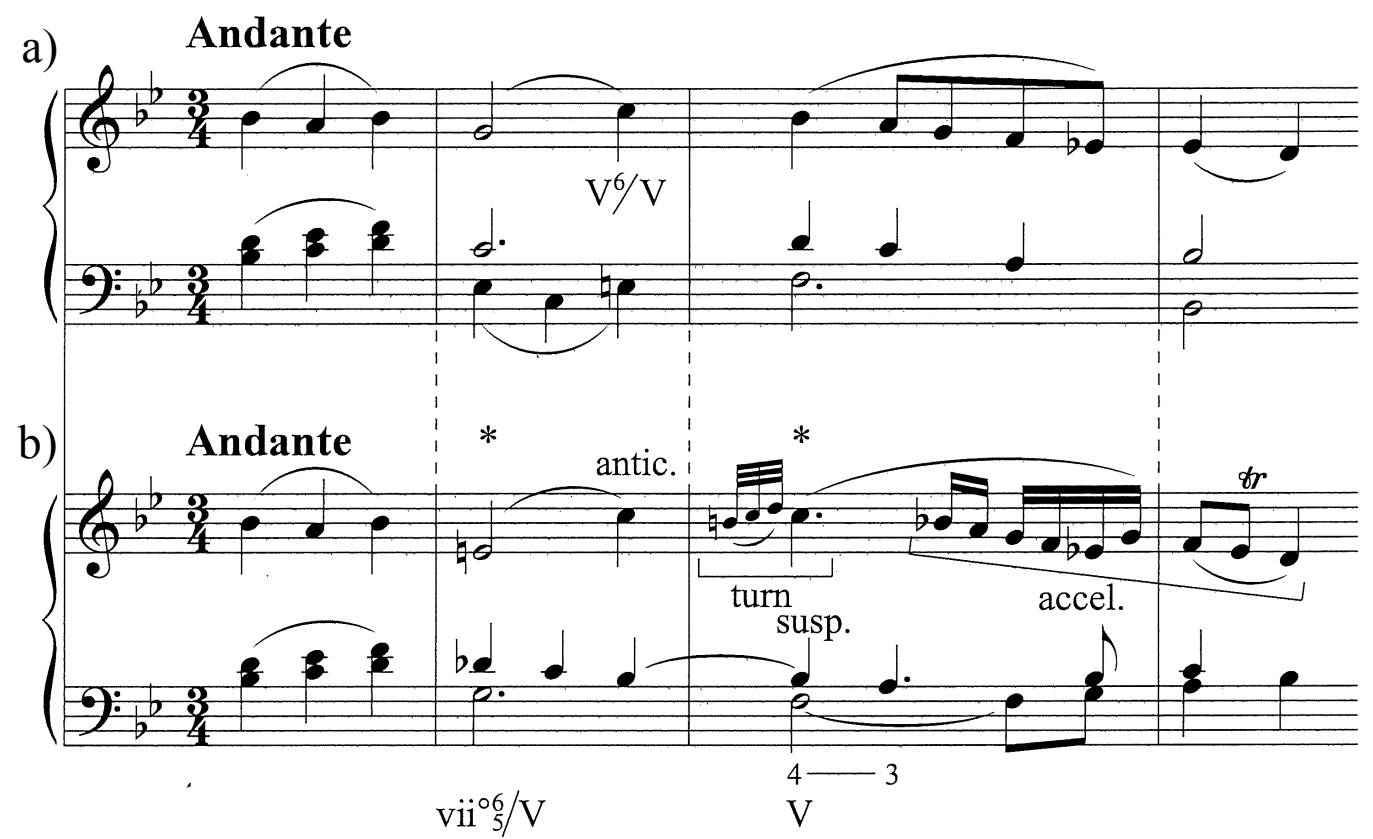

Example 2a-b: Mozart, Piano Sonata in F Major, K. 533, second movement - 2a) Opening theme recomposed; $2 b)$ Mozart's theme as actually composed.

Let's go into the next example. Now, here I also have examples from Bach. You may have noticed my first book concentrated on Beethoven, the second book spread it out Mozart and Schubert on either side, and now this book will be very easy to criticize because I talk about music from Hildegard of Bingen all the way to Shostakovich, Stravinsky, and Schoenberg. There is no way that one person 
can competently speak about all of this music, but I found wonderful examples and I wanted to suggest what I mentioned in my opening remarks that indeed this notion of virtual agency has a history, that composers were successively finding ways of staging these agential affects. This example is a particularly interesting one. It is one that Raymond Monelle first used in his book "Linguistics and Semiotics in Music" (1992) to illustrate my concept of troping. And what we find is a fugue subject which is very gallant and then with its answer we find a countersubject that has the passus duriusculus (or the lament bass kind of descending chromaticism). Now, later Bach does exploit its characteristic passus duriusculus affect, but one could also say that at the beginning the parallel thirds are such a strong scaffolding for the counterpoint that we might hear the chromaticism simply as chromatic passing tones, nothing more than that. And, here it has a kind of almost pastoralized merging of purport because in effect both voices are basically descending in terms of their structural scaffolding and this is one of the ways in which counterpoint can enable you to bring together opposing topical expressions into a singular expression. In other words, a singular melos.

Now, there are two possible interpretations, as I say. On the one hand, you could call this a discursive trope. In other words, you preserve the independent auctorial aspect of each line and have them in dialogue throughout. The other way would be to merge them in as a kind of melos into a single tropologically enriched line, a single expressive line doubled, if you will, in two voices. Now, that may sound like almost the same thing but there are slight differences here. In the first case, we have two actors. In the second, we have one agent or even one virtual subjectivity and this notion of melos that enables us to put these things together. So, that is a very striking example where the countersubject is radically different from the subject, but of course they are brought into alliance through the notion of parallel thirds or sixths which is what I call the contrapuntal scaffolding that we find underlying most of Bach's subjects and countersubjects. It is part of the inventioning, if you will, as Laurence Dreyfus called it in his book "Bach and the Patterns of Invention" (1996). 


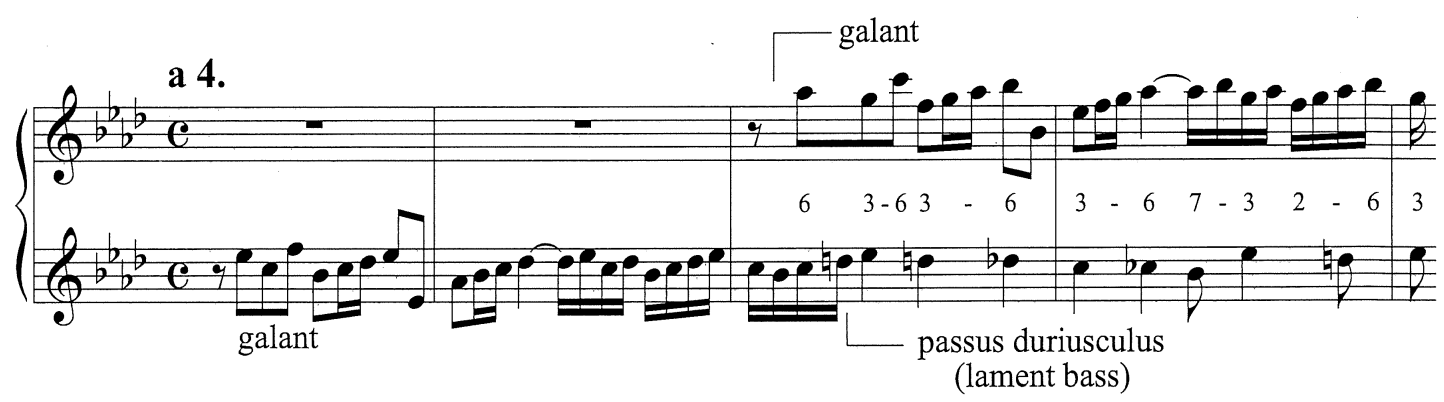

Example 3: Bach, Fugue in Ab Major (WTC II); galant subject and lament countersubject, two oppositional topics that combine in $\mathrm{mm}$. 3-5 to create a striking trope.

Let's go to the next example (Ex. 4a-c). Here, from the Sinfonia in D Minor, the 3-part invention. We see what I like to call refractive counterpoint in which the countermaterial is derived from the subject (see Ex. 4a). You can see that in the left hand the pick-up into m. 2 echoes and then reverses the direction of the right hand's motive. That is one form of refractive counterpoint, when you derive material from the subject. Another form can be seen in m. 4, where you simply, on the surface, use parallel thirds, sixths, or tenths to double a single voice. This is an early example of planing in the sense that you are simply enriching a single line rather than literally producing two lines. And, of course, it happens with the second note of the answer in $\mathrm{m}$. 3. Instead of having a countersubject in the soprano, we simply double the subject in thirds. The lower voice is, in a sense, even its opposition and contrary motion, creating a sense of potential unification.

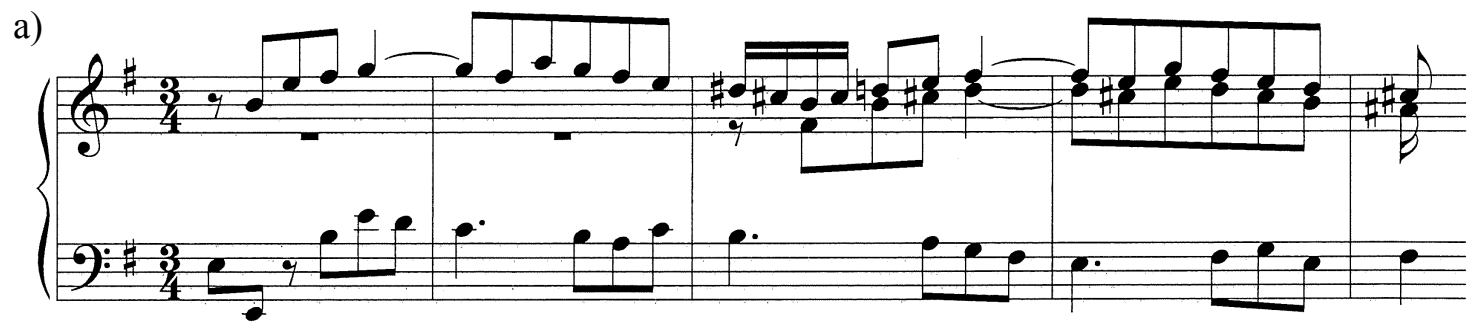

Example 4a: Bach, Sinfonia in E Minor (BWV 793): "refractive counterpoint" (countermaterial derived from the subject).

So, why would Bach do this? And why, for example, would Beethoven do it in his two countersubjects for his Hammerklavier fugue, which are also derived from the subject? Well, for both composers there is going to be a later emergence 
of, in Beethoven's case, a new subject which will become the countersubject in the double fugue that happens at the end of the finale. For Bach, in m. 14, a series of sixteenth notes provide a derived counter set (see Ex. $4 b$ ). Notice how the sixteenth notes are like a diminution of the initial countermaterial back in $\mathrm{m}$. 1 . So, now we have derived an actual countersubject which will get used against the subject in this developmental section of the Sinfonia - which just cadenced on the dominant key of B minor. We will go as a typical Durchführung, now leading through keys. That will go through a series of keys as Bach dramatically exploits his now completely unified, even though clearly contrapuntal texture. You will see the third voice, for example in $\mathrm{m} .16$, is just a quick little fake-stretto entry and basically the middle voice is just echoing things. That is more of a two-voice structure here, but it gets enriched by that third voice harmonically (of course, Bach is thinking harmonically as well as contrapuntally).
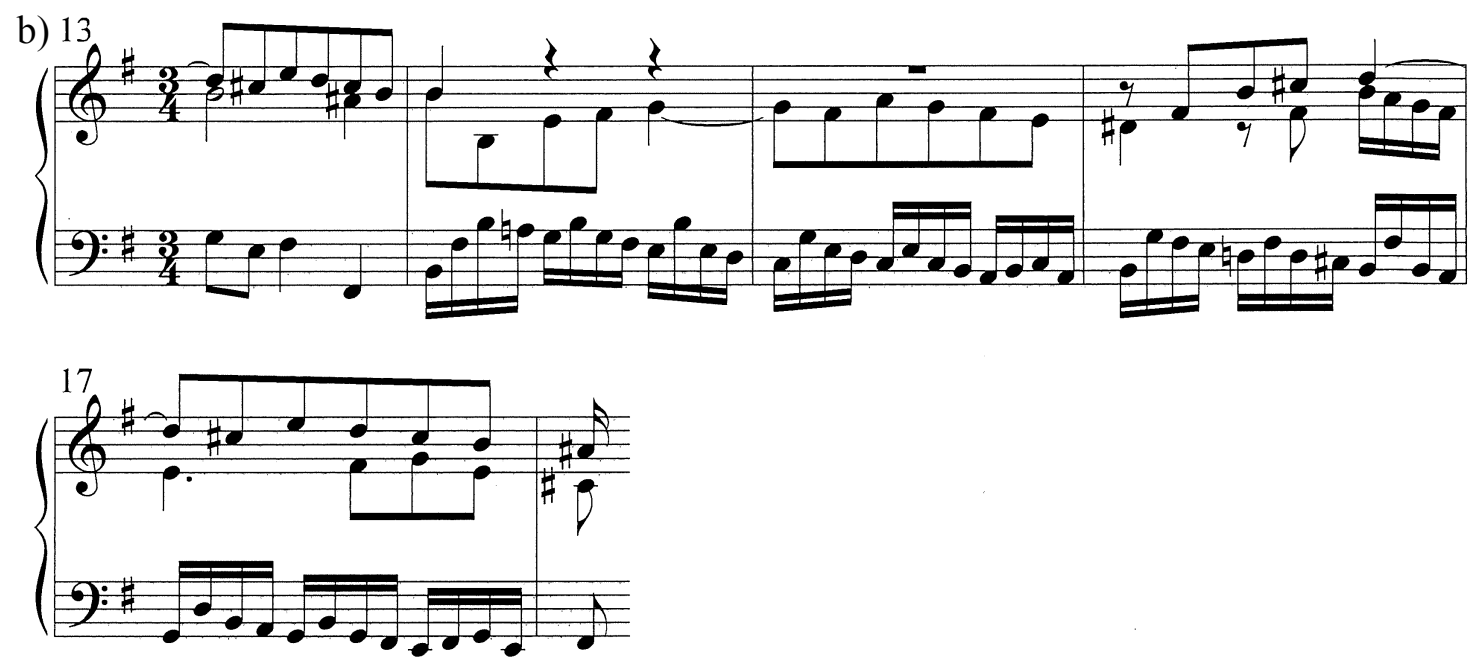

Example 4b: Bach, Sinfonia in E Minor, derivation of a countersubject (left hand, $\mathrm{m}$. 14ff.) from the countermaterial (and hence, from the subject itself).

Let's go to Ex. 4c. What I call the developmental section ends interestingly not on a dominant to prepare for the return, but on a dissonant diminished seventh, a moment of dubitatio, if you think of it in terms of Baroque rhetoric. At this point, we return to E minor but in an unstable way because that diminished seventh is going to frame the entire return. See how it appears again at extreme registers in $m .42$, downbeat (the $D \#$ is down an octave and the $C$ is up an octave), and that is the dramatic, tragic climax of this miniature expressive genre. You 
could almost think of the symphony as being little tone poems in terms of their dramatic trajectories, not in terms of their explicit program of course.

Now, let's look at the quasi-stretto. Stretto is one of the means by which this notion of refractive counterpoint or melos is most obvious. It is almost the trivial example of melos or refractive counterpoint. Here, we just have a quasistretto: you can see it in the soprano in $\mathrm{m} .37$, then in the bass, and then echoed in the alto. What is fascinating is that you can find still another quasi-stretto in just two voices: the pick-up to m. 41 in the alto, then you have it in the soprano from the $\mathrm{E}$ to the $\mathrm{A}$, and at the same time you have the $\mathrm{E}$ to the $\mathrm{A}$ echoed in the alto voice towards the end of $\mathrm{m}$. 41. So again, these are stretto effects. All the while, our original or our derived countersubject is wandering its way deeper and deeper into the depths. And, this notion of a wedge-like contrary motion, these wedge effects are often culminating effects for Bach in which he tries to create a kind of, I guess we could use the term plenitude, a registral plenitude of texture, in this case, in which he creates the sense of intensification that is so characteristic often times that the ultimate climax of a work by Bach happens near the end (as we can see in this entire return section, which is basically further developing towards the ultimate crisis climax in $\mathrm{m}$. 42 before working its way down in this twisted, painful fashion and only in the very last measure as though an external agency had provided it the major triad).
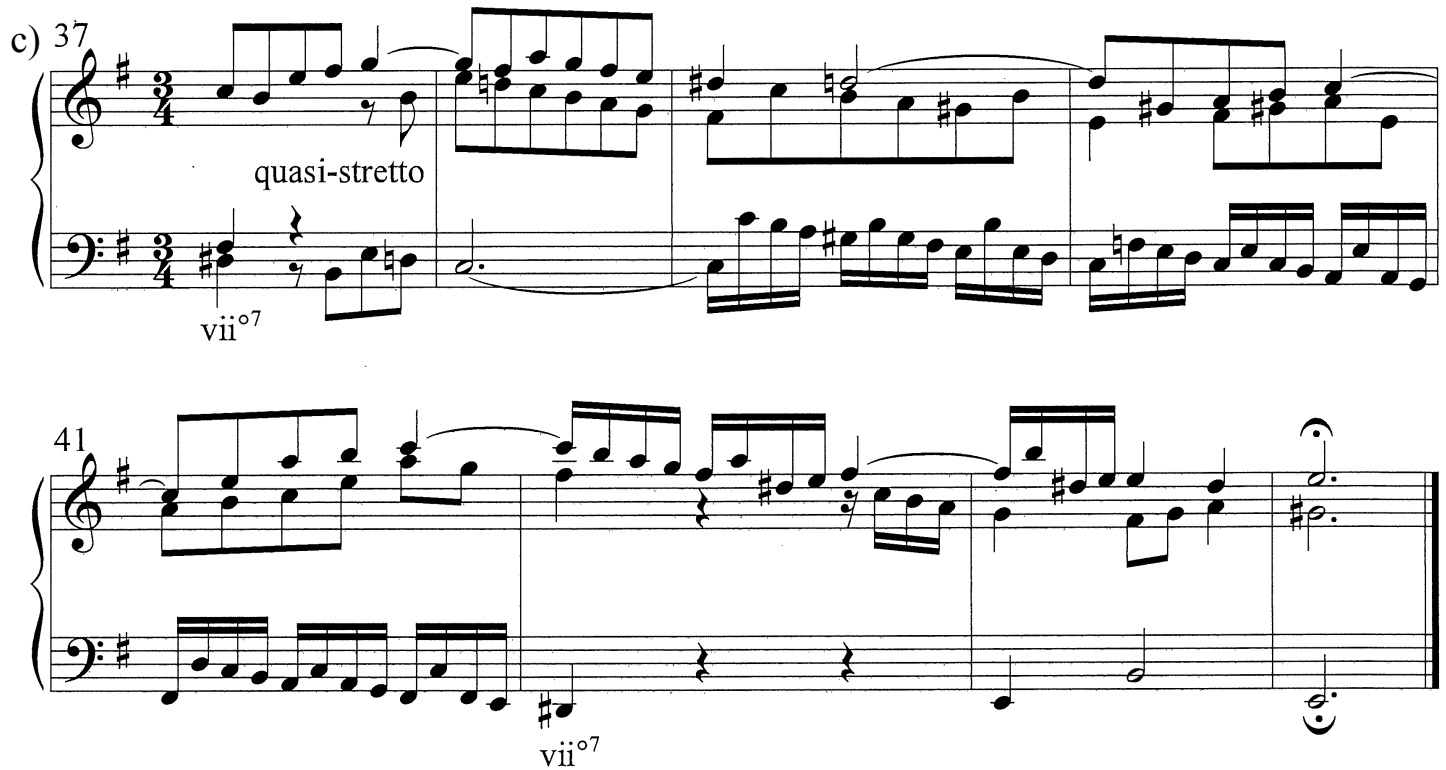

Example 4c: Bach, Sinfonia in E Minor, return of the subject (quasi-stretto) in E minor, framed by diminished-seventh chords. 
So, let's move forward to Chopin. This is in the chapter where I talk about the contributions of performance to understanding, but I also use this piece, this first page in particular, to talk about ways in which we can infer culmination, ways in which we can infer types of actions, agents, actors, and ultimate subjectivity. Now, the introduction (see Ex. 5), as you could see from my analysis (the first three systems leading to the fermata) is all in C major. We only know it is going to be the dominant of $\mathrm{F}$ minor when we get the le-fi in $\mathrm{m} .8$ at the a tempo ( $C$ going to $\mathrm{D} b$ and then to $\mathrm{B} \sharp$ - that instantly twists that $\mathrm{C}$ into a dominant of $\mathrm{F}$ minor at which point we get the main theme). However, this introductory music, as unmarked as it is harmonically, could almost be taken as a kind of a pastoral actantiality in the sense that nothing is happening here that is necessarily human yet. It is the backdrop for a human drama and hence it is more like a natural actantial, unspecified agency, if you will. The source being perhaps the wind or, if you were in another context, the waves or whatever. Anything that is just unspecified at this point and happens over and over. It liquidates through those fragmentary repetitions and sets us up for a much more direct melodic expressivity - melody and accompaniment in a clear textural format.

Now, the accompaniment in this 6/8 measure we can understand as two $3 / 8$ measures. That kind of waltz hypermeasure, if you will. This is very useful for Chopin because he can play on where the downbeat is in his hypermeasure, which he does. He starts with his presumed hypermetric downbeat in the middle of the $6 / 8$ measure. But that is where things actually begin in spite of the notation. He does it that way, I suspect, because he wants to reach a notated hypermetric downbeat on the very last measure of this page in $A b$ major. Now, the theme is outlining the diminished chord and it is very internalizing. Its very inwardnessinward "shapeness", if you will-and reflectivity, self-reflectivity are emphasized by the fact that he simply repeats it. But then, where I have marked B (the motive B) you see the letter " $\mathrm{I}$ ". That comes from, I would argue, the introduction. What was unmarked in the introduction is now taking on more of a role in the agential, maybe even auctorial role. Auctorial in the sense that it is being used at the very moment where Chopin turns from dysphoric $\mathrm{F}$ minor to euphoric $\mathrm{A} b$ major. In other words, he is echoing the beautiful pastoral, natural sensibility of serenity of the opening at the very moment he is turning to that same serenity in his theme. 

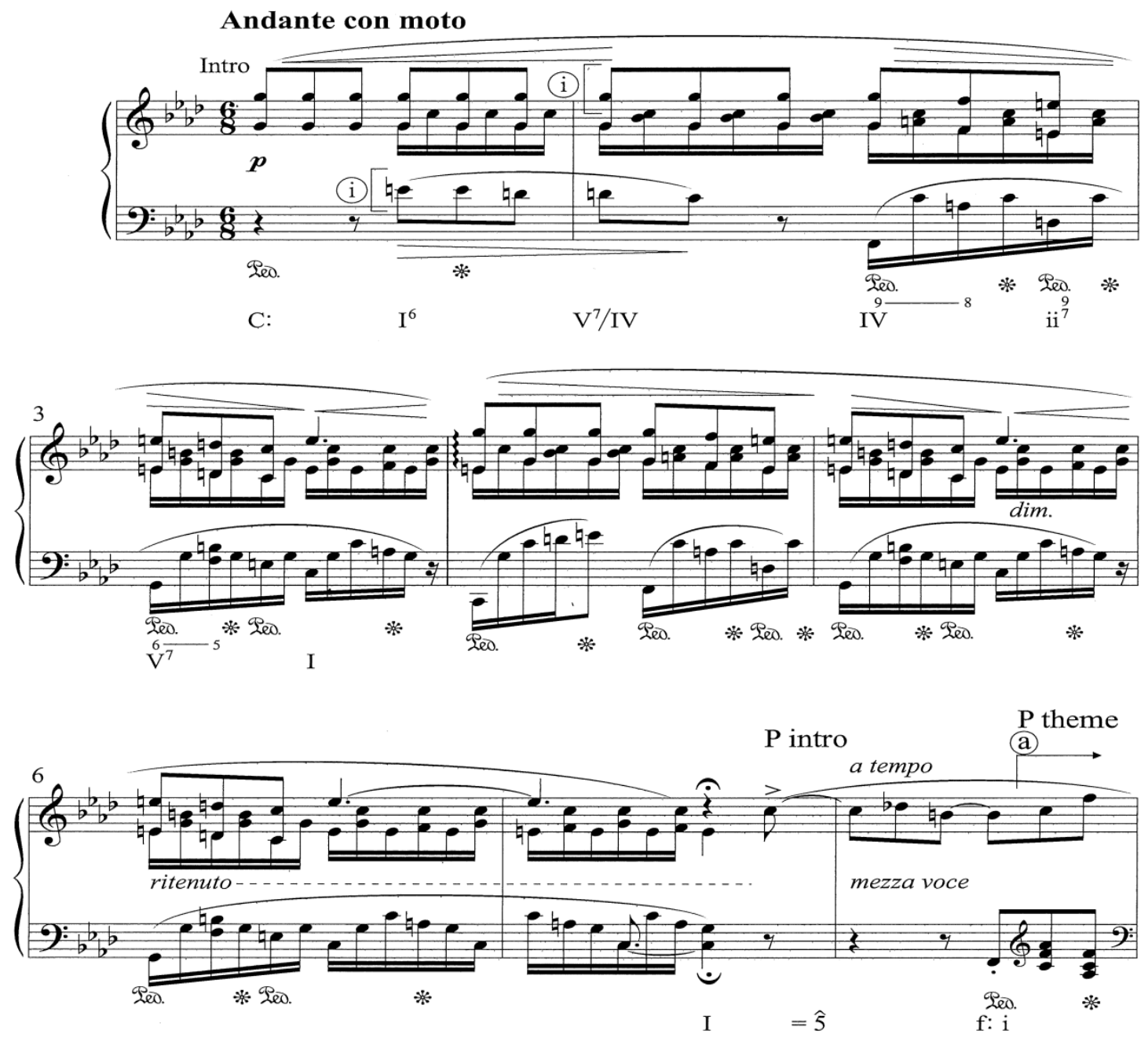

(b) (i) frag.

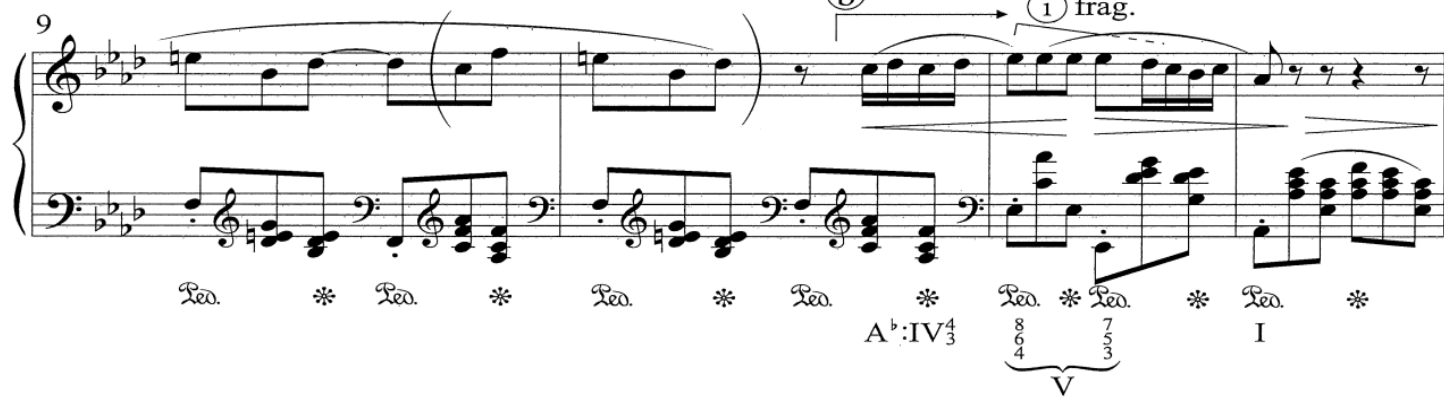

Example 5: Chopin, Ballade in F Minor, Op. 52, introduction and first theme. 


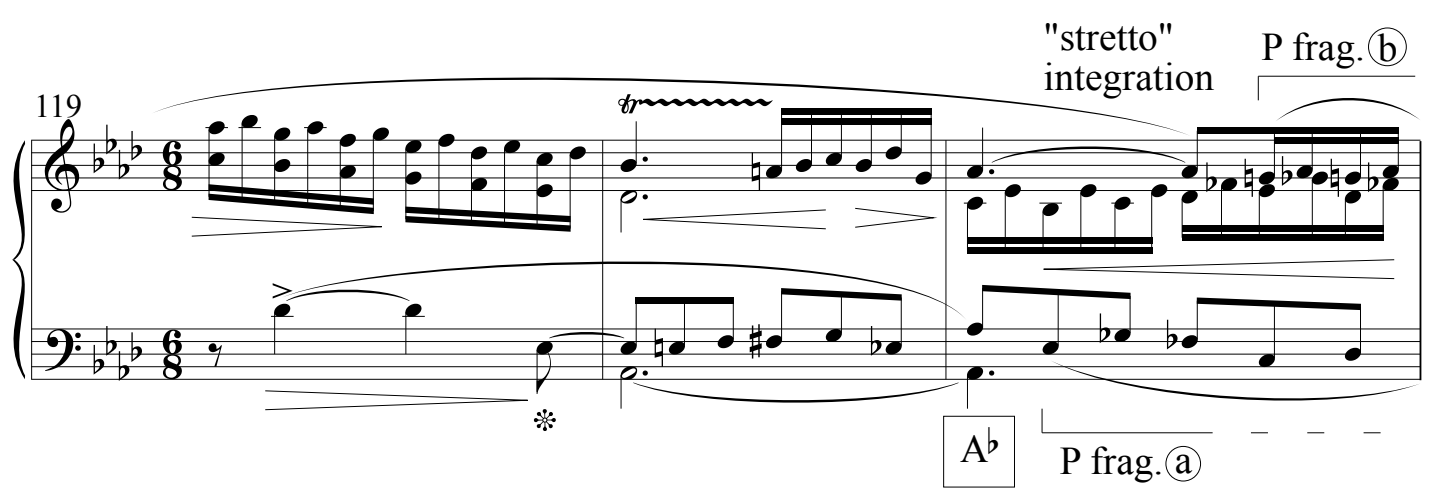

P frag. b

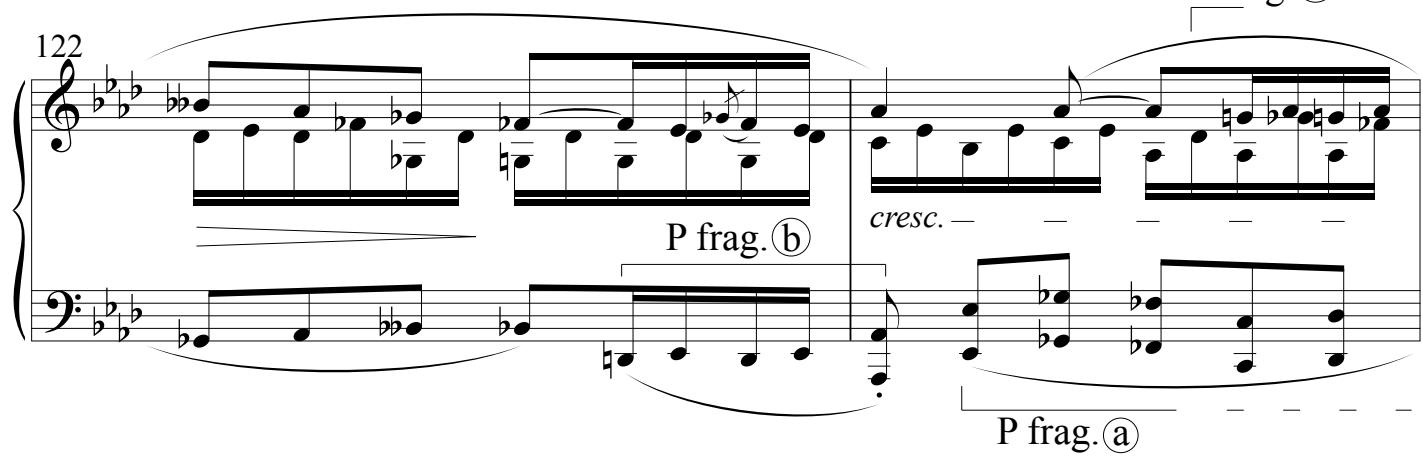

climactic integration

(i) frag.
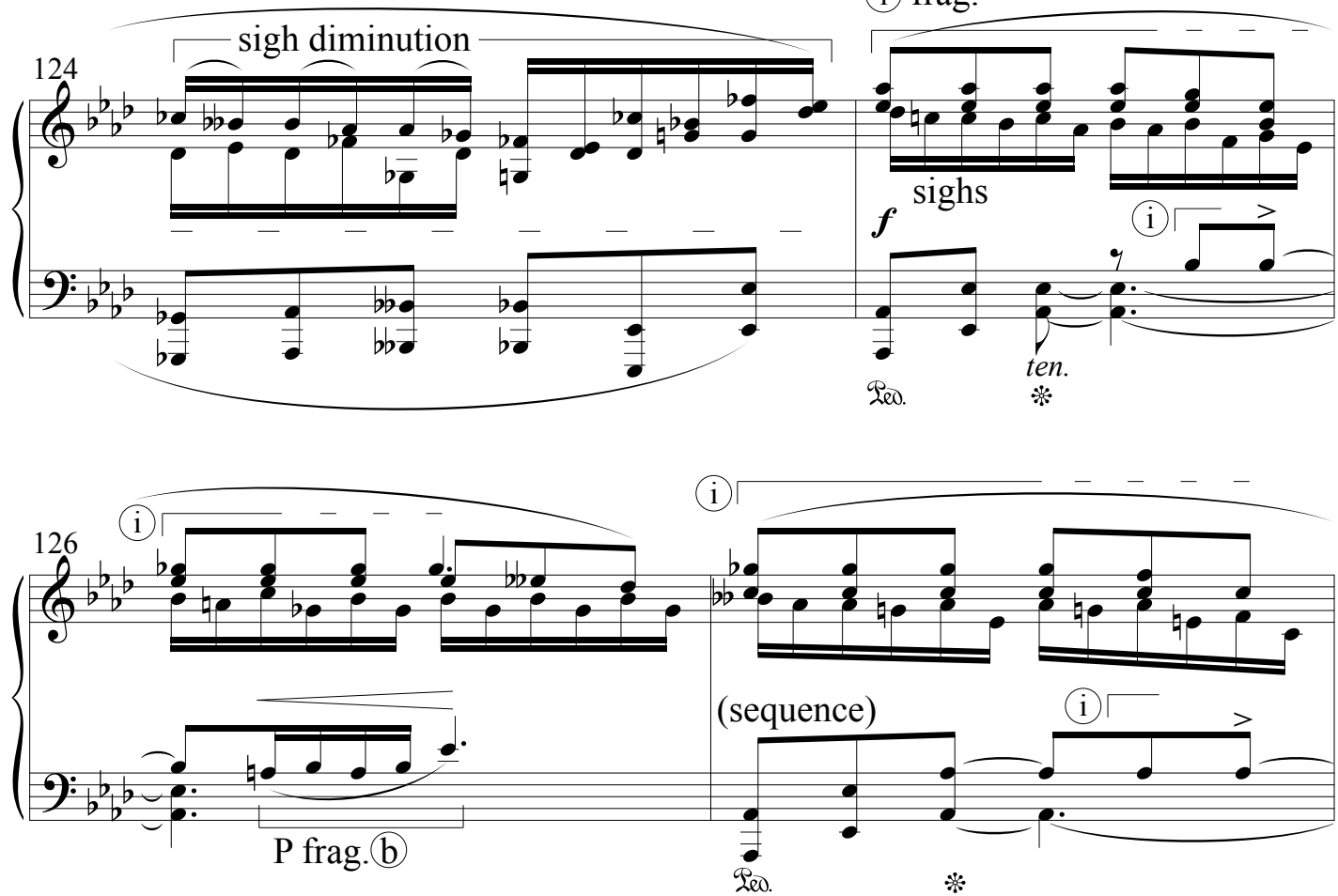

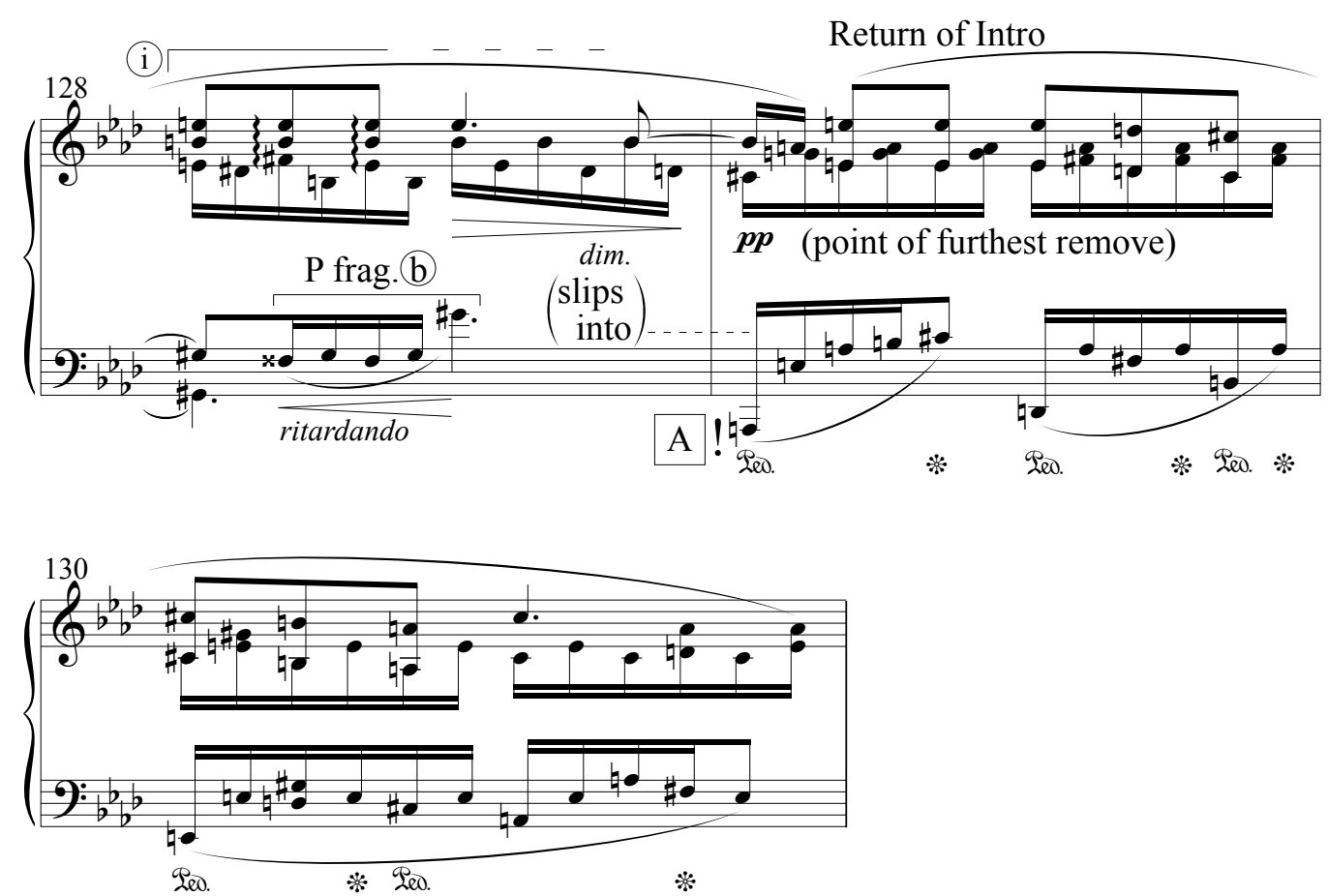

Example 6: Chopin, Ballade in F Minor, Op. 52, Integrative developmental climax and "return" via intro in A major.

Let's move on to our last example (see Ex. 6). It is hard to argue that this piece is a sonata, but it certainly is in dialogue with sonata aspects. One thing it is not like sonata is that its second theme is in $\mathrm{B} b$ major and it comes back and resolves itself, if you will, in $\mathrm{D} b$ major with an apotheosis of plenitude, if you will, as well. Edward T. Cone was the one who first called it an apotheosis (Cone 1968, pp. 85-86). The example that I am showing you on this page is either at the end of the exposition, having moved ultimately to $A b$, or part of a plenitude of thematic integration, which is still developmental. It is an ultimately developmental passage that is leading ultimately to m. 125 , which is the climactic integration of all three motives that I have analyzed on the first page-a very heroic moment of affirmation. It is just not a theme that you can fit into a typical analysis. In a wonderful analysis that Michael Klein gives of narrativity in this Ballade (2004), it gets neglected. But it is a central moment, an integrated moment in which integration can be used to affirm as well as to continue to develop. So, we have a kind of strettoing of our fragments that keeps building to this forte in m. 125 and then dissolves, sequentially liquidates, if you will, and melts into a return of the very opening, but not in $\mathrm{F}$ minor or $\mathrm{F}$ major or $\mathrm{C}$ major or anything that you might expect, rather in A major and hence a point of furthest remove in 
a developmental sense. After this little introduction, you may recall that the gradual return happens through ricercar-like imitations of the opening motive that keep querying: where are we? where are we going to go? In other words, this heroic affirmation in m. 125 along with the affirmation of that $\mathrm{B} b$-theme returning in $\mathrm{D} b$ major are the hopeful endings that are ultimately denied by the chaotic ultimate turn towards the tragic of the closing of this Ballade. So, in other words, the second theme and its resolution are within the sphere of the wished for or the hoped for, not in the sphere of the actual, tragic which is the home key of F minor. So, what counts as ultimate resolution in F minor is its ultimate tragic inability to escape from the tragic resolution by means of these heroic and apotheotic-over the edge as it is-climaxes. So, we leave with a sense of frustration.

That is a quick tour through some music examples and we can certainly return to these if you have further questions, but now it is time for your specific questions.

\section{Ensuing conversation with guests from TeMA}

Maria Lúcia Machado Pascoal: In your book A Theory of Virtual Agency, after some considerations about intertextuality in Beethoven's music (quoting Michael Klein and your own writings), you reach the following conclusion:

“... relevant intertextual connections enhance our understanding of a given musical work from the perspective of later works, not just prior ones. Thus, for contemporary listeners the virtual subjectivity of a musical work has a future as well as a past" (Hatten 2018, p. 142).

Can you elaborate this point of view? Isn't there a danger for hermeneutics to become mere subjectivity?

Robert Hatten: Intertextuality, according to Michael Klein, works both from the past and from the future of a given work. In my historical reconstructions of interpretive meaning, I would like to think that a work is only in dialogue with that which came before, but inevitably, my perspective from the present affects how I interpret the past. However, there is a difference: a composer cannot directly quote or allude to a work that has yet to be written. Rather, the composer 
may anticipate a musical process, or suggest a topic, that becomes clear for a present-day interpreter only from the perspective of a later, perhaps more foregrounded manifestation of that process or topic. Yes, there is a danger that hermeneutics may become too subjective in this way, but if we presume a counterbalancing grounding in a musical style, we have a more rigorous "methodological dialectic" that can focus on the semiotic interpretation of a work in its historical contexts. I might be criticized for taking too Romantic a perspective on dramatic trajectories in Bach, for example, but even if my work with Beethoven may have suggested such expressive journeys, I can nevertheless make a case for Bach's dramatic shapes without intertextually referencing Beethoven. (For example, in my analysis and interpretation of the Sinfonia in E minor, Hatten 2018, p. 103).

Cristina Capparelli Gerling: Please elaborate on, and perhaps exemplify, item 7 of your book:

"The extent to which a virtual human agency appears to cohere and sustain an identity across change, interpreting some change as internalized growth and persisting throughout a work (e.g. through motivic developing variation, as part of a musical discourse)" (Hatten 2018, p. 69).

Robert Hatten: A simple example would be associating a virtual agent with a musical theme. Developing variation is one way in which that theme can gradually evolve, such that its changes can be understood as growth of a single theme, hence a single agency, rather than suggesting a competing theme or agency.

Cristina Capparelli Gerling: Your analysis of the Eb-minor Bach Prelude is a masterpiece. Particularly, I want to express my heartfelt thanks for all the commentaries and explanations on Brahms's piano music. As a piano teacher, Brahms piano music poses a tremendous challenge to most students. Concerning this passage:

"Brahms's extended descent through two more thirds creates an effect akin to slipping away from both (metric) time and (tonal) space. The further sense of temporal stretching, emphasized by the careful attention to 'every note' in Brahms's note to Clara, may suggest an early move toward interiorization, a 
virtual subjectivity ruminating over deepening pools of potential reflection, if you will. Have we reached a point in music history where virtual subjectivity can be staged in five notes?" (Hatten 2018, p. 121).

Why did you stop at the question mark?

Robert Hatten: My rhetorical question, can virtual subjectivity be staged in five notes, was meant to provoke thought. Beethoven was able to stage the essence of tragedy in four notes, with the subject head of his string quartet fugue in C\# minor, the first movement of Op. 131. But it took him some sketching to settle on the right four notes: scale degrees $\hat{5}-\hat{7}-\hat{1}$ (on a weak beat) all suggest hope and resolution (but metrically undermined); the fourth note, lowered $\hat{6}$, is gesturally a reversal of direction, emphasized as a negation by the sforzando emphasis and the stylistic reversal from implied major to inescapable minor. This hopeful setup and sudden negative reversal is a musical analogue to the structure of tragedy in drama. Of course, the number of notes isn't the point. Other cues for interiority include rhetorical gestures and pauses of all sorts. The theme by Brahms suggests interiorizing by continuing a process beyond its conventional boundaries, and thus it constitutes a dissolving rather than a breaking or dramatic reversal of those boundaries. It's a prolonged sigh that implies inexorable sinking into melancholy, if you will.

Cristina Capparelli Gerling: Your books and articles generally illuminate and often even guide a particular resolution of an interpretative problem. In addition, these readings enable my imagination to act upon the text as "emotional unfolding".

\section{Flavio Santos Pereira: You wrote:}

"It is imaginatively interactive participation [...] that I investigate in this book under the rubric of virtuality" (Hatten 2018, p.2).

What do you understand by "imaginatively interactive participation" and how can this concept be applied analytically? How does "virtuality" condition this concept?

Robert Hatten: "Imaginatively interactive participation" is another way of describing "engagement" - how a listener becomes involved in identifying with 
an inferred virtual agency - "imagined," since the agency is virtual and not actual; "interactive," since it requires a willingness to interpret by "participating" in the journeys of that agency and relating them to one's own journeys-either physically as a body in space, or cognitively as an unfolding complex of emotions and thoughts, or some combination of these.

Flavio Santos Pereira: There are numerous recurrences of the term "subjectivity": virtual subjectivity; intense experience of subjectivity; virtualizing and fictionalizing subjective engagement; enlarging your subjective awareness; conceptions of musical subjectivity; the emergence of subjectivity; staging of subjectivity; multiple, errant or alternate subjectivities; robust subjectivity. What is the relationship between "imaginatively interactive participation" and "subjectivity"?

Robert Hatten: Subjectivity is of course a huge concept. For my purposes, I decided to limit its scope to one's healthy (hence, "robust") consciousness and self-awareness, and to demonstrate some of its historically established aspects using Boethius's The Consolation of Philosophy from 524 A.D. as an example predating most Western music, and widely read over a thousand years (Hatten 2018, p. 139-42). These include: freedom of thought; framed within (inner) dialogue; fusing emotion and thought to achieve moral emotions; the capacity to experience cathartic emotions; and to experience mixed emotional thought or conflict; self-reflectivity and self-reflexivity as the ability to consider one's state from a higher perspective; intertextually expanded consciousness as informed by one's culture; and the capacity to realize the actual from the virtual or allegorical-believing oneself into an envisioned state. Of course, it is one thing to experience all of these things personally and another to find them staged in a work of music. And it takes "imaginatively interactive participation" to go beyond merely identifying them and instead, by identifying with them, to negotiate a rich and aesthetically warranted experience of virtual subjectivity as activated by one's own subjectivity.

Diósnio Machado Neto: Could you develop briefly the concept of "plenitude" in relation to the negotiation strategy between the expressive field and the formal 
design, after your statement that plenitude "need not be tied to a particular affective state"?

Robert Hatten: "Plenitude" is a means of thematic and textural completion that has a long history, from the saturation of texture by rhythmic diminutions or thematic and textural intensification through stretto, to the integration of thematic material. Such filling of textural/thematic space can suggest fulfillment, and hence completion. Typically, that fulfillment is experienced as blissful-but not always. It can be experienced as an intensification of any prevailing affect, even dysphoric ones. As blissful, it is a useful strategy for enhancing any expressive genre or dramatic trajectory that moves toward transcendence. A parallel concept is apotheosis, the kind of aggrandizement of a theme that includes saturation and dynamic intensity.

Diósnio Machado Neto: You wrote that expressive genres are based on a broad and consolidated negotiation between expressive fields and formal schemes. This opens up the possibility of finding consolidated expressive genres, such as the tragic-transcendent, but also it may result in a local and unique expression. Based on that, would it be possible, within the mentality of the galant style, to establish a relationship between expressive genre and local discursive concepts, seeking to systematize changes in consolidated models and/or new formulas of expressive genres in force in a given space-time?

Robert Hatten: I would agree that plenitude can occur locally - in fact, I interpret such a case in the third movement of Beethoven's String Quartet in Bb, Op. 130 (Hatten 2004, p. 43-51). Here, early plenitude is achieved, but cannot be sustained - and thus, the local topic becomes a global premise.

For the galant style, plenitude is typically achieved through progressively diminutional variations, whether in variation sets or in aria-like contexts, where the da capo elaborations can create similar effects. In his book, Music in the Galant Style (2007), Robert Gjerdingen would likely argue against the kinds of dramatic trajectories I find in Mozart, since for galant music, "courtly listening habits seem to have favored music that provided opportunities for acts of judging, for the making of distinction, and for the public exercise of discernment and taste" (p. 
4). And while that may be true for earlier Mozart, there is ample evidence in the works themselves for the claims I make about later works of Mozart.

Guilherme Sauerbronn de Barros: "... the 'doctrine' of a thinker is that which remains unsaid within what is said." (Martin Heidegger, Plato's Doctrine of Truth, Cambridge, 1998)

As you once pointed out in Interpreting Musical Gestures, Topics and Tropes (2004), the common-sense opposition between structure and expression should be reviewed for the sake of interpretation. In this sense, interpretation should be capable of bringing structure to the fore without giving up expression or, conversely, translating expressive patterns into actual sound without losing its structural roots. ${ }^{3}$ In your last book, you went further and defined this "multilevelled integrative discourse" as melos: "[In Chapter 4] I elaborate a fresh concept of musical melos - with special attention to techniques that enhance the integration of melody with counterpoint, harmony, and motive - as support for the continuity of agents through the unfolding of a musical discourse" (Hatten 2018, p.12). Schenker, despite dismissing the need of a particular performance for a musical work to exist, was clearly aware of the power of musical gesture in guiding or losing the listener and coined the concepts of "dissembling"4 and "framing touch" (Rahmenanschlag) (among others) to bridge the gap between background and foreground.

$3 "(. .$.$) there may be higher-level gestures that a performer employs to help direct the listener's$ attention to the main structural outlines of a form, or an expressive genre. Such gestures play a narrative role at a higher level, not unlike the abstract pointing gestures that may accompany speech, as analyzed by the linguist and psychologist David McNeill (1992). They may also be inferred as part of the work, even in the absence of specific notational marking, given an understanding of the style." (Hatten 2004, p.95).

4 "The mere fact that our notation hardly represents more than neumes should lead the performer to search of the meaning behind the symbols. [...] the author's mode of notation does not indicate his directions for the performance but, in a far more profound sense, represents the effect he wishes to attain [...]. In this case, the pianist would have to sacrifice adhering precisely to the printed text. [...] Here lies the true secret of art of performance: to find those peculiar ways of dissembling through which-via the detour of the effect-the mode of notation is realized." (Schenker 2000, pp. 5-6).

5 "The term Rahmenanschlag, literally translated as 'framing touch' refers to a kind of touch that brings greater emphasis to certain notes in order to distinguish these, usually the carriers of the main melodic line, from the lighter 'embellishing' tones that are being framed, as it were." (Schenker 2000, p.90, n. 3). 
Could you relate your concept of melos to Schenker's dissembling and framing touch and, in relation to musical notation, comment on the power of musical gesture to unveil the "hidden music behind the score"?

Robert Hatten: Melos is an important bridging concept in the move from multiple actants (gestures, motives, individual lines) to their integration into singular agents. I wanted to demonstrate some of the ways composers have staged this kind of integration, and it led me to propose concepts such as refractive counterpoint (where countermaterial is derived from the substance of a subject, for example) to explain the fusion of multiple voices into a single agency with a coordinated purport. Bach's Sinfonias in E minor and F minor provide excellent examples, as do Beethoven's fugal expositions from the finale of the "Hammerklavier" Piano Sonata in Bb, Op. 106, which set up his integrative double fugue (and a glorious plenitude when he tropologically combines the heroic $\mathrm{B} b$ with the spiritually acceptant $\mathrm{D}$ major subjects).

Schenker's concepts of "dissembling" and "framing touch" are not directly related to melos, but one might make the connection by noting how performance is another means of "staging" agential integration, by revealing the hierarchical relationships among pitches and bringing out those structural lines that form the backbone of themes. However, I would also argue against playing an analysis, by didactically bringing out such middleground lines, since there is too much gestural meaning that can be lost if one does not also respect the character of the surface - what I like to call the "irreducible significance of the surface" - which should also be projected in performance. The theorist who best provides access to these complementary approaches is Alexandra Pierce. In her book, Deepening Musical Performance through Movement (2007), she offers heuristic exercises that encourage "Schenkerian hearing" in coordinating deeper structural progressions with surface characterizations, or "tones of voice," that respect affect-filled gestures and contours. Finding the right balance is possible, as I have learned in using these exercises with my students in a graduate class at the University of Texas, "Performance and Analysis." And in this sense, I agree that there is power in musical gesture to unveil the hidden music behind the score. 
Paulo de Tarso Salles: You mention that the performer is an "actual agent" in the sense that he/she is "the agent who is producing the sound". On the other hand, you wrote: "The critical starting point for my theory is the capacity to imagine a virtual agency in the sounds themselves. Thus, a music-internal action implies a virtual actant" (Hatten 2018, p. 19).

Is this related to the role of the narrator communicating the musical narrative in a time different from the action? Can the virtualization process be understood as the fruition of the sound expression through a narratorinterpreter?

Robert Hatten: I have a special place for both performative and narrative agency in my theory, and I devote a chapter to the possibilities of each. But to answer your question more directly, yes, the performer may function as an actual narrative agent who "tells" the events of a virtual musical story, perhaps providing a personal perspective on those events, bringing out some at the expense of others, and so forth. The performer's recognition and interpretation of the disposition through virtual agents will help guide a performative projection of whatever story is there to be "narrated." What becomes especially interesting is when the work stages its own, virtual narration - and this is often cued by a striking rhetorical gesture that provokes a shift in level of discourse, such that we hear subsequent music as commenting on prior music, as though from a higher, reflective level. And this capacity for staging self-reflectivity is also what leads to the staging of virtual subjectivity - the interiority is marked by the music's capacity to comment upon it by stepping outside of the situation. When, for example, in the addendum to Beethoven's finale from the "Serious" String Quartet in F Minor, Op. 95, an ongoing tragic discourse is suddenly undermined by completely unprepared, buffa hilarity, I would agree with Rey Longyear's assessment that this is a case of Romantic irony, and one marked by “annihilating laughter," in Jean Paul Richter's terms (Longyear 1970, p. 145-62).

Back to the performer: one can perform from inside, taking the stance of the virtual agency who, for example, experiences shock or surprise at an unexpected event, or one can take the opposite stance, that of the presumed narrative agency of the composer, by identifying with that creative agency capable of injecting, willfully, such surprises. For the latter, imagine the performer in the position of a magician who astounds the audience with sleight 
of hand without projecting any personal identification with that surprise (see, for example, the discussion in Virtual Agency, 2018, p. 227).

\section{References}

1. Cone, Edward T. 1968. Musical Form and Musical Performance. New York: Norton.

2. Dreyfus, Laurence. 1996. Bach and the Patterns of Invention. Cambridge: Harvard University Press.

3. Gjerdingen, Robert. 2007. Music in the Galant Style. New York: Oxford University Press.

4. Hatten, Robert. 2004. Interpreting Musical Gestures, Topics, and Tropes: Mozart, Beethoven, and Schubert. Bloomington: Indiana University Press.

5. _. 2018. A Theory of Virtul Agency for Wetern Art Music. Bloomington: Indiana University Press.

6. Klein, Michael L. 2004. Chopin's Fourth Ballade as Musical Narrative. Music Theory Spectrum, v. 26, pp. 23-55.

7. Longyear, Rey. M. 1970. Beethoven and Romantic Irony. In: Lang, P. H. (ed.). The Creative World of Beethoven, ed. Paul Henry Lang. New York: Norton.

8. Monelle, Raymond. 1992. Linguistics and Semiotics in Music. Chur: Harwood Academic.

9. Pierce, Alexandra. 2007. Deepening Musical Performance through Movement: The Theory and Practice of Embodied Interpretation. Bloomington: Indiana University Press.

10. Schenker, Heinrich. 2000. The Art of Performance. Ed. Heribert Esser e trad. Irene Schreier Scott. New York: Oxford University Press. 